\title{
DYSEMBRYOPLASTIC NEUROEPITHELIAL TUMOUR - REPORT OF A RARE CASE
}

\author{
K. Valarmathi' ${ }^{1}$ S. Brihadisvarar ${ }^{2}$, R. Sathyalakshmi'3 ${ }^{3}$ S. Mary Lilly ${ }^{4}$ \\ 1 Professor, Department of Pathology, Stanley Medical College, Chennai. \\ 2Postgraduate Student, Department of Pathology, Stanley Medical College, Chennai. \\ ${ }^{3}$ Assistant Professor, Department of Pathology, Stanley Medical College, Chennai. \\ ${ }^{4}$ Professor, Department of Pathology, Stanley Medical College, Chennai.
}

\section{ABSTRACT}

\section{BACKGROUND}

Dysembryoplastic Neuroepithelial Tumour (DNET or DNT) is an unusual and rare brain tumour commonly occurring in younger age groups with excellent prognosis following surgery. This is a case report of an 18-year-old male, with pharmacoresistant seizures diagnosed as dysembryoplastic neuroepithelial tumour, followed by a brief discussion of the histopathological features and clinical behaviour of the tumour.

\section{KEYWORDS}

Dysembryoplastic Neuroepithelial Tumour, Specific Glioneuronal Element, Oligodendrocyte Like Cell, Floating Neuron.

HOW TO CITE THIS ARTICLE: Valarmathi K, Brihadisvarar S, Sathyalakshmi R, et al. Dysembryoplastic neuroepithelial tumour Report of a rare case. J. Evolution Med. Dent. Sci. 2016;5(104):7699-7701, DOI: 10.14260/jemds/2016/1737

\section{BACKGROUND}

Dysembryoplastic neuroepithelial tumour is a rare, low-grade, mixed neuronal and glial tumour, usually presenting as pharmacoresistant, focal or secondarily generalised seizures from childhood. It was first described by Daumas-Duport et-al in 1988.[1]

Features of dysembryoplastic neuroepithelial tumour include a characteristic multinodular architecture, involvement of supratentorial cortex (primarily the cortex of temporal lobe), unusual involvement of subcortical white matter, presence of both neuronal and glial components with little cytological atypia if any and surrounding cortical dysplasia.[1,2,3,4]

Prognosis is favourable following surgery.[5] Differentiation of dysembryoplastic neuroepithelial tumour from other low grade gliomas is important as DNET does not usually recur after surgery and so postoperative radiation and chemotherapy are not required (both of which have adverse effects on children).[5,6]

\section{CASE REPORT}

An 18-year-old male presented with refractory epilepsy for the past 13 years. He was born out of a non-consanguineous marriage, with a normal birth history and psychomotor development. Family history of CNS malformations and tumours were ruled out. Seizures started when the patient was 5 years old and were pharmacoresistant. The seizures were complex partial with secondary generalisation.

Complete neurological examination and routine laboratory investigations were within normal limits. MRI revealed a $5 \times 3.5 \times 2.5 \mathrm{~cm}$ space occupying lesion in the left anterior temporal lobe which was hyperintense on $\mathrm{T} 2$

Financial or Other, Competing Interest: None.

Submission 15-11-2016, Peer Review 18-12-2016,

Acceptance 24-12-2016, Published 29-12-2016.

Corresponding Author:

Dr. S. Brihadisvarar,

Department of Pathology,

Stanley Medical College,

Chennai-1.

E-mail: brihadisvarar@gmail.com DOI: $10.14260 /$ jemds $/ 2016 / 1737$ weighted imaging and hypointense on T1 weighted imaging, with heterogenous contrast enhancement, intralesional calcification and without any surrounding oedema.

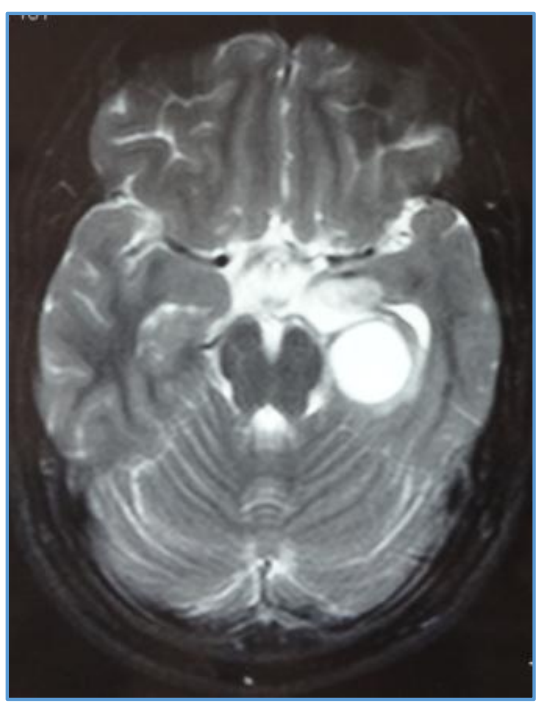

Figure 1. MRI, T2 weighted, Axial view showing hyperintense space occupying lesion in the temporal lobe

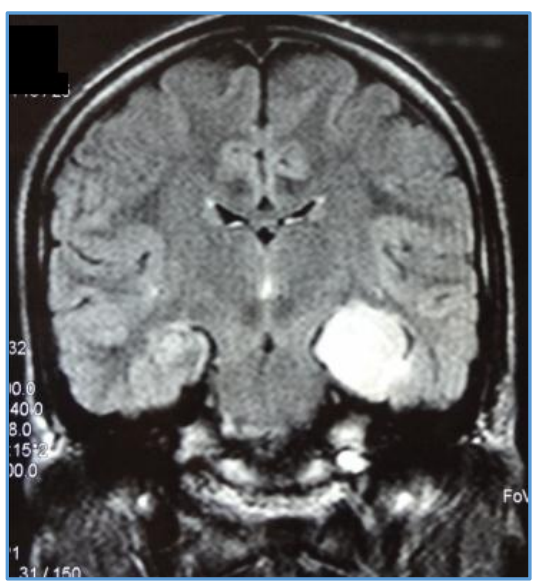

Figure 2. MRI, T2 weighted, coronal view showing hyper intense space occupying lesion in the temporal lobe cortex. Note the absence of peri-tumoural oedema or mass effect 
After obtaining informed written consent, left frontotemporal craniotomy, with subtotal excision of the space occupying lesion was performed, and the specimen was sent for histopathological examination.

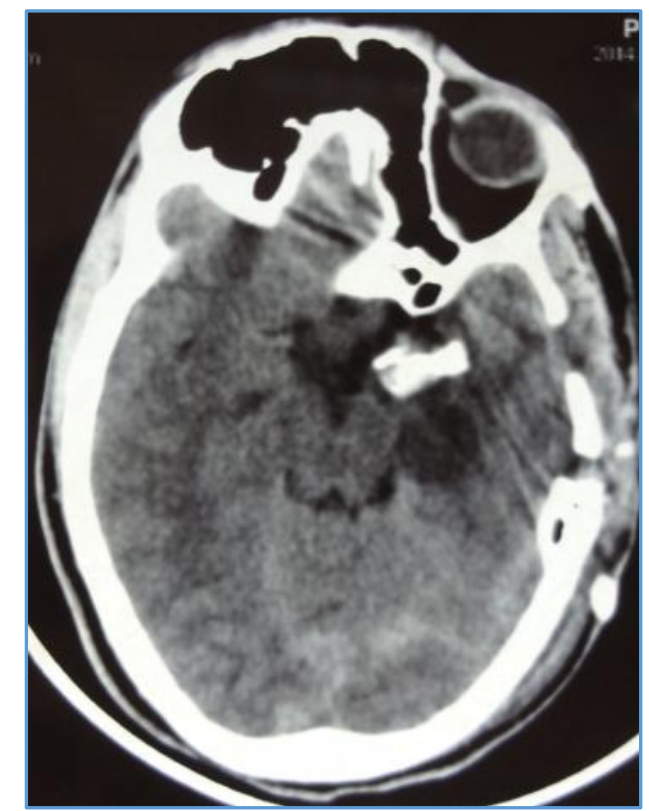

Figure 3. Post-operative CT, taken after subtotal excision of the tumour

Macroscopically, a lobulated grey-white soft tissue was received, measuring $0.5 \times 0.3 \times 0.2 \mathrm{~cm}$.

Microscopic examination showed brain parenchyma with adjoining neoplasm composed of microcystic spaces lined by oligodendrocyte like cells in a mucinous background, floating neurons and focal areas showed myxoid change. Calcospherites were seen between tumour cells, and areas of haemorrhage were also seen. Immunohistochemistry showed the tumour to be positive for S100.

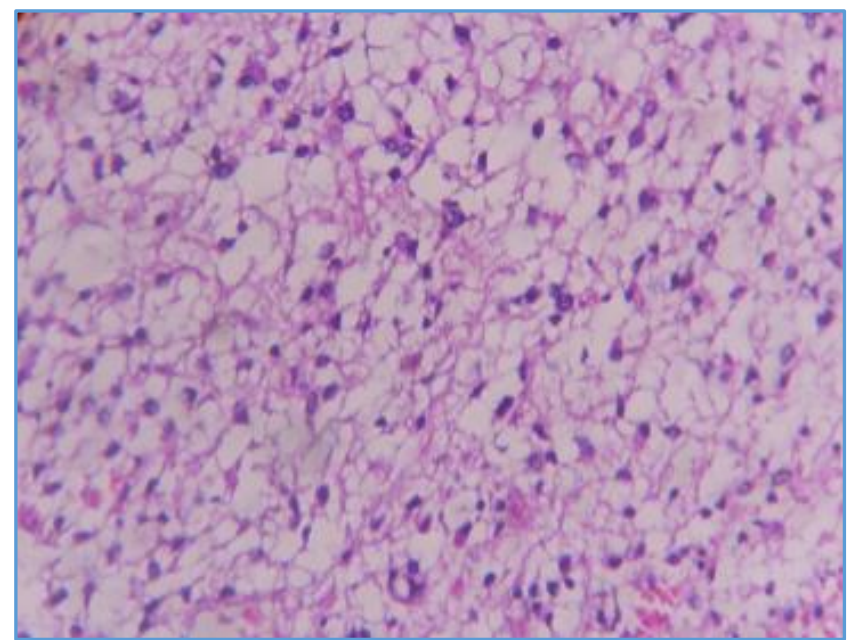

Figure 4. Microphotograph, 40X magnification showing oligodendrocyte like cells with perinuclear halo in a myxoid background, microcystic spaces, and floating neurons

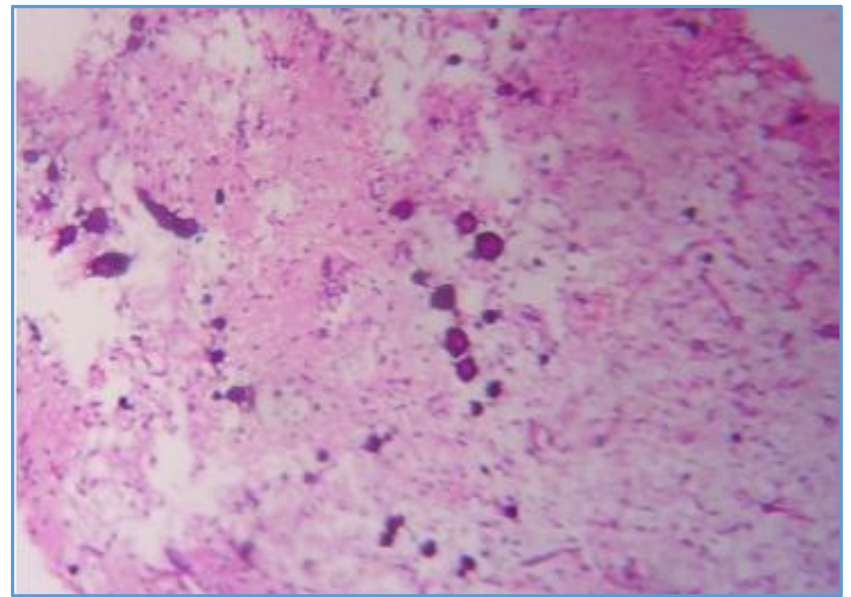

Figure 5. Microphotograph showing calcospherites

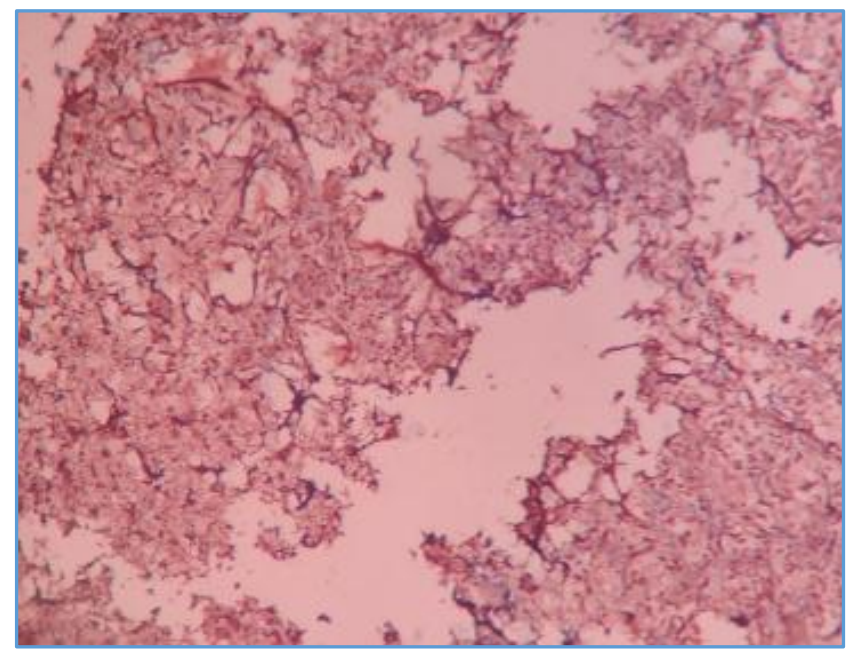

Figure 6. Microphotograph showing S100 positivity.

A diagnosis of dysembryoplastic neuroepithelial tumour was made.

\section{DISCUSSION}

DNET is a rare, benign tumour of the CNS, first described by Daumas-Duport et al in 1988.[1] DNETs comprise about 1-2 \% of CNS neoplasms, occurring mainly in children and young adults with an equal sex distribution. They commonly present as pharmacoresistant intractable seizures.[1,2] DNET is the diagnosis in up to $20 \%$ of patients undergoing temporal lobe surgery for epilepsy.

DNETs were considered to have an embryonal origin, [1] but showed a less aggressive clinical course compared to other embryonal CNS tumours (Which are classified as grade 4 lesions by the WHO). Hence, the term "dysembryoplastic" was coined to denote both their supposed origin and clinical behaviour. The WHO has classified DNET in the category of neuronal and mixed neuronal-glial tumours, corresponding to grade $1 .[7]$

DNETs are soft and gelatinous with multinodular architecture, occupying commonly the supratentorial cortex with unusual subcortical white matter involvement if any.[1,2] Other reported locations include septum pellucidum, caudate nucleus, brain stem and cerebellum. Neuroradiological features aiding diagnosis include their location within an expanded cortical ribbon, remodelling of adjacent calvarium, and the lesion being $\mathrm{T} 1$ hypointense and $\mathrm{T} 2$ hyperintense with multinodular architecture on MRI imaging and absence of mass effect or oedema.[8] 
Microscopically, the hallmark of DNET is the presence of Specific Glioneuronal Elements (SGNE), which are columns of axons, lined by uniform oligodendrocyte like cells (OLC) in a background of mucinous matrix, with microcyst formation and intervening floating neurons.[1,2,3,4] Additionally, scattered astrocytes, adjacent cortical dysplasia and rare mitotic figures may be present.

Three types of DNET have been described. The simple type which contains only specific glioneuronal elements, the complex type which has glial nodules made of masses of oligodendrocyte like cells, with internodular specific glioneuronal elements and adjoining cortical dysplasia ${ }^{1}$ and the nonspecific type which has neither the specific glioneuronal elements nor the multinodular architecture, microscopically resembling low grade gliomas, but with clinical and radiological features of DNET. $[3,4,8]$

Immunohistochemistry and special stains show that oligodendrocyte like cells are positive for S100, neurons show positivity for synaptophysin, NeuN and neurofilament protein, glial cells are positive for GFAP and mucin stains with Alcian blue.

Growth fraction measured with Ki67 antibody is usually below $1 \%$.

The diagnosis of DNET is made on the basis of clinical and radiological features and by the demonstration of SGNE on histopathological examination. $[1,3,4,8]$

Most patients with DNET show excellent prognosis following surgery, with good seizure control and minimal to nil neurological deficits.[5,6] No radiation or chemotherapy is required, unlike other low grade gliomas. Therefore, DNETs need to be accurately diagnosed by the pathologist.

Most published series show a stable clinical course of patients undergoing surgery for DNET. Only rarely do these tumours recur. Other recent case reports have shown that DNETs may very rarely undergo malignant transformation. ${ }^{[9,10]}$ Since it has only been 25 years since DNET was first described and also due to low incidence rate of this tumour, their natural history has not yet been completely elucidated. But these reports underscore the importance of regular follow-up of patients diagnosed and treated for DNETs.

\section{CONCLUSION}

DNET is a relatively rare brain tumour and needs to be differentiated from other CNS tumours with similar histopathological appearance by the pathologist, due to its favourable prognosis.

Recently published works show a potential for recurrence and malignant transformation, in a small subset of DNETs, which shows the importance of clinical follow-up.

\section{REFERENCES}

1. Daumas-Duport C, Scheithauer BW, Chodkiewicz JP, et al. Dysembryoplastic neuroepithelial tumor: a surgically curable tumor of young patients with intractable partial seizures. Report of thirty-nine cases. Neurosurgery 1988;23(5):545-56.

2. Daumas-Duport C. Dysembryoplastic neuroepithelial tumours. Brain Pathol 1993;3(3):283-95.

3. Daumas-Duport C, Varlet P, Bacha S, et al. Dysembryoplastic neuroepithelial tumors: nonspecific histological forms: a study of 40 cases. J Neurooncol 1999;41(3):267-80.

4. Honavar M, Janota I, Polkey CE. Histological heterogeneity of dysembryoplastic neuroepithelial tumour: identification and differential diagnosis in a series of 74 cases. Histopathology 1999;34(4):342-56.

5. Chan CH, Bittar RG, Davis GA, et al. Long term seizure outcome following surgery for dysembryoplastic neuroepithelial tumor. J Neurosurg 2006;104(1):62-9.

6. Nolan MA, Sakuta R, Chuang N, et al. Dysembryoplastic neuroepithelial tumors in childhood: long-term outcome and prognostic features. Neurology 2004;62(12):2270-6.

7. Louis DN, Ohgaki H, Wiestler OD, et al. The 2007 WHO classification of tumours of the central nervous system. Acta Neuropathol 2007;114(2):97-109.

8. Stanescu CR, Varlet P, Beuvon F, et al. Dysembryoplastic neuroepithelial tumors: CT, MR findings and imaging follow-up: a study of 53 cases. J Neuroradiol 2001;28(4):230-40.

9. Hammond RR, Duggal N, Woulfe JM, et al. Malignant transformation of a dysembryoplastic neuroepithelial tumor. Case report. J Neurosurg 2000;92(4):722-5.

10. Rushing EJ, Thompson LD, Mena H. Malignant transformation of a dysembryoplastic neuroepithelial tumor after radiation and chemotherapy. Ann Diagn Pathol 2003;7(4):240-4. 